\title{
Flower-visiting and pollen-carrying arthropods of Leucojum aestivum L. (Amaryllidaceae) in wild, reintroduced and ex situ populations
}

\author{
Livilla Angela Maggi • Thomas Abeli $\mathbb{D} \cdot$ Graziano Rossi • Mauro Gobbi
}

Received: 9 February 2021 / Accepted: 17 June 2021 / Published online: 30 June 2021

(C) The Author(s) 2021

\begin{abstract}
Leucojum aestivum L. is a wetland-dependent perennial geophyte occurring in Europe and western Asia. It is self-incompatible, with high level of fruit-set and seed-set. Yet, its pollinators are poorly known. Here, we present the most recent research on potential pollinators of L. aestivum. We collected data on flower-visiting and pollen-carrying arthropods in three populations of the species in the River Po plain (N-Italy), where L. aestivum occurs mainly in forests with Alnus glutinosa and Fraxinus sp. pl. close to rivers. We studied a wild population, a new reintroduced population and an ex situ population located at the Botanical Garden of the University of Pavia. Our study identified 18 arthropod taxa carrying L. aestivum
\end{abstract}

Communicated by E. T. F. Witkowski.

Supplementary Information The online version contains supplementary material available at https://doi.org/10.1007/ s11258-021-01154-0.

L. A. Maggi · G. Rossi

Department of Earth and Environmental Sciences,

University of Pavia, Via S. Epifanio 14, 27100 Pavia, Italy

T. Abeli $(\bowtie)$

Department of Science, University of Roma Tre, Viale

Guglielmo Marconi 446, 00146 Roma, Italy

e-mail: thomas.abeli@uniroma3.it

M. Gobbi

Section of Invertebrate Zoology and Hydrobiology, MUSE-Science Museum, Corso del Lavoro e della Scienza, 3 I, 38122 Trento, Italy pollen; the soft-winged flower beetle Dasytes plumbeus (Coleoptera: Melyridae) and the sac-spider Clubiona sp. pl. (Araneae: Clubionidae) were the most frequent visitors. Hymenoptera only occasionally visited $L$. aestivum flowers (e.g. the sweat bee Lasioglossum punctatissimum). D. plumbeus, the long-horned beetle Grammoptera ruficornis (Coleoptera: Cerambycidae), Clubiona sp. pl. and L. punctatissimum resulted in the taxa with the highest average abundance of pollen grains on their body suggesting a potential role in L. aestivum pollination. Differences in flower-visiting and pollen-carrying arthropods were observed between the three populations, with a decreasing taxonomic diversity of visiting species from the wild population to the ex situ population. Our results, based on direct observation in the field, are partially in contrast with a previous study on L. aestivum pollinators that suggested diurnal and nocturnal Lepidoptera and occasionally bees as main pollinators for the species.

Keywords Amaryllidaceae $\cdot$ Clubiona $\cdot$ Dasytes plumbeus $\cdot$ Lasioglossum punctatissimum . Restoration $\cdot$ Pollination biology 


\section{Introduction}

Leucojum aestivum L. subsp. aestivum (L. aestivum hereafter) is a geophyte in the Amaryllidaceae family (Parolo et al. 2011). It is an C-S-European/W-Asiatic plant species and its range extends from Ireland in the north to N-Italy in the South, and from Middle East (Iran and Caspian See) to W-France in the West (Parolo et al. 2011). L. aestivum is listed in the global IUCN red list as least concern (Lansdown et al. 2014), but it is locally threatened (e.g. VU in Italy, Orsenigo et al. 2021; see also Parolo et al. (2011) for an overview of the national status of $L$. aestivum in Europe) and thus a species of conservation interest, locally. It grows in wetland plant communities, like wet forests in the lowland river valleys and in wet meadows, near different types of water bodies such as rivers, swamps and lake shores, banks of canals and periodically inundated sites, from 0 to $350 \mathrm{~m}$ a.s.l. (Kasermann and Moser 1999; Parolo et al. 2011). In northern Italy, the wetlands where L. aestivum grows are island-like fragments of natural and semi-natural habitats in a landscape dominated by crops. The small size of suitable habitat has negative consequences on L. aestivum population size and density and on pollinator availability, also declining as a consequence of habitat fragmentation and pesticides (Brittain et al. 2010). Population isolation due to habitat fragmentation results in a low within population genetic diversity and a medium-high genetic differentiation among $L$. aestivum populations in northern Italy (Gentili et al. 2018). Although L. aestivum is scattered in northern Italy, river flooding and pollinators may have a role in maintaining the gene flow among populations (Gentili et al. 2018).

The perianth of $L$. aestivum is composed of six white tepals in two whorls, 13-22 mm long, with a green spot just below the tip of each tepal. Flowers are grouped in number of 2-8 in an apical inflorescence subtended by a spathe. Each plant can produce up to three inflorescences, but most commonly only one. $L$. aestivum is self-incompatible and there is no apomixis, thus the reproductive success of this plant depends entirely on pollinators (Parolo et al. 2011).

In their monograph on the species, Parolo et al. (2011) report a study by Knuth (1909), indicating diurnal and nocturnal Lepidoptera and Hymenoptera as the most likely pollinators of L. aestivum. Except for this old study, no recent quantitative research has been performed on pollinators of this species.

In the only other species in the genus Leucojum ( $L$. vernum $\mathrm{L}$.), the floral morphology suggests pollination by Hymenoptera, Apidae in particular, buzz-pollination (Fishchuk and Odintsova 2020). L. aestivum has very similar flowers to $L$. vernum, thus it can be hypothesised a similar pollination mechanism is used in this species. However, pollinator visitations on $L$. aestivum are infrequent (Wisdom et al. 2019). Possible reasons for this may be reconducted to the early spring flowering period, when pollinator activity is still scarce, to the preference of pollinators for open habitats (Abeli et al. 2013; Gargano et al. 2017), to the lack of nectar as a reward (Parolo et al. 2011) and the lack of a scent. A recent study showed that $L$. aestivum does not produce any volatile organic compound (Abeli et al. 2016). Therefore, pollinator attraction in L. aestivum is mainly visual and probably deceptive, as the green marks in the tepals may suggest the presence of nectar, which occurrence is not demonstrated. Rather, these green marks may have a role in provisioning the seeds with photosynthetate like in Galanthus nivalis L. (Aschan and Pfanz 2006).

Such a generalist pollination system is expected to benefit early blooming species in habitat where pollinators are typically scarce, like the riparian woodlands where L. aestivum grows (Alonso 2004). Indeed, the study of fruit set highlighted that $L$. aestivum pollination system is quite effective, with values of fruit set close to $100 \%$ in most cases (Parolo et al. 2011). Nevertheless, L. aestivum seed set is often pollen limited (average seed set $33.8 \%$ ), especially in low-density populations (Parolo et al. 2011). In a translocation of L. aestivum in N-Italy, Abeli et al. (2016) created two populations characterised by different densities, with the low-density population half-dense the high-density one. After five years from plant release, the latter (high-density) population showed higher fruit set and recruitment than the lowdensity population.

Seed set and density are often positively correlated, because higher numbers of flowering plant individuals per square metre are more attractive for pollinators, consequently, a greater quantity of pollen grains are available for the fertilisation of the ovules (Dauber et al. 2010).

Given the importance that pollinators have in the reproductive success of $L$. aestivum, in this study, we 
investigated the flower-visiting and pollen-carrying arthropods at the southern range edge of the species, in the plain of the River Po (Northern Italy) in three different populations: a large wild population, a population recently reintroduced and an ex situ population cultivated in a botanical garden. The aim of the study is to identify potential pollinators of $L$. aestivum in Northern Italy by collecting the flowervisiting arthropods found on it and investigating the presence of pollen belonging to L. aestivum on their body.

\section{Materials and methods}

\section{Study populations}

Three spatially distinct populations were chosen for the present study in the Po Valley, in the Province of Pavia (Lombardy, N-Italy): a wild population of $L$. aestivum located within the special area of conservation (SAC) IT2080019 "Boschi di Vaccarizza" (Municipality of Linarolo), a reintroduced population located within the SAC IT2080007 "Garzaia di Bosco Basso" (Municipality of Breme and Sartirana Lomellina) and an ex situ population located at the Botanical Garden of the University of Pavia, inside the city of Pavia (Fig. 1).

The SAC IT2080019 site "Boschi di Vaccarizza" (45.14914 N; $9.25385 \mathrm{E} ; 61.3 \mathrm{~m}$ a.s.1.) is located along the course of the Po River, and it is characterised by a well-preserved wood of Black Alder (Alnus glutinosa (L.) Gaertn.) and White willow (Salix alba L.). Here, L. aestivum is dominant in the understorey and grows in a stable population at the edge of a small ditch bordering a farming land. During the flowering period (April-May) L. aestivum represents the only flowering species in the understorey.

The population of $L$. aestivum located at "Garzaia del Bosco Basso" (45.11840 N; 8.64288 E; 106.5 m a.s.l.) was established in 2016 in the context of a reintroduction programme of the species promoted by the local government of Pavia Province. This location is characterised by the presence of habitat 91E0 (see above), with Black alder (A. glutinosa), Goat willow (Salix caprea L.), thick reeds with dominance of the marsh reed (Phragmites australis (Cav.) Trin. Ex Steud.) and (Typha latifolia L.) growing around a spring locally called "fontanile", and it is entirely surrounded by cultivated areas and poplar groves.

Compared to Vaccarizza, the alder grove is mainly formed by low- and medium-height trees which ensure a very dense vegetation cover, also in the understorey. Vaccarizza is characterised by tall trees and an almost total absence of shrubs in the understorey.

The Botanical Garden of the University of Pavia (45.18572 N; $9.16349 \mathrm{E}$; $75 \mathrm{~m}$ a.s.l.) is located in the city centre of Pavia and it covers about two hectares and hosts a gymnosperm arboretum, an angiosperm arboretum, officinal plants and many other threatened species of conservation interest (Clauser and Pavone 2016). In the botanical garden, about 1,000 plants of $L$. aestivum from about 15 populations from N-Italy are grown in a small nursery. Plants are grown in groups of 10-20 individuals in plastic containers (ca. $50 \mathrm{~cm}^{3}$ volume), without holes in the bottom to maintain the soil fully wet during the growing season, from February to June. During the flowering period of $L$. aestivum, other co-flowering species in the botanical garden include Prunus spp., Quercus ilex L., Castanea sativa Mill., Laurus nobilis L., Hyacinthoides hispanica (Mill.) Rothm, Malus domestica Borkh., Diospyros kaki $\mathrm{L}$.

Sampling of the flower-visiting arthropods

L. aestivum populations were investigated in 2017 and 2018.

In 2017, we visited the study populations during the flowering period in April-May twice a week; we captured all arthropods visiting or found near (i.e. a few $\mathrm{cm}$ ) the flowers of L. aestivum with an entomological net or directly with plastic test tubes. The tubes containing the entomological samples, were dated and coded. In detail, in each day, five 30-min sampling sessions were performed in the morning (10 am), at noon $(12 \mathrm{am})$, in the afternoon $(3 \mathrm{pm})$, at twilight $(8 \mathrm{pm})$ and at night $(9 \mathrm{pm})$. Temperature during the sampling sessions were measured by using a DataLogger Geoprecision at 10' intervals. In year 2017, sampling was done during the entire $L$. aestivum flowering period, while in 2018 it was decided to focus on April only and on the time slots with the greatest presence of arthropods based on the results of 2017. Specifically, in the following time slots: in the morning $(10 \mathrm{am})$, at noon $(12 \mathrm{am})$, in the afternoon (3 pm). 


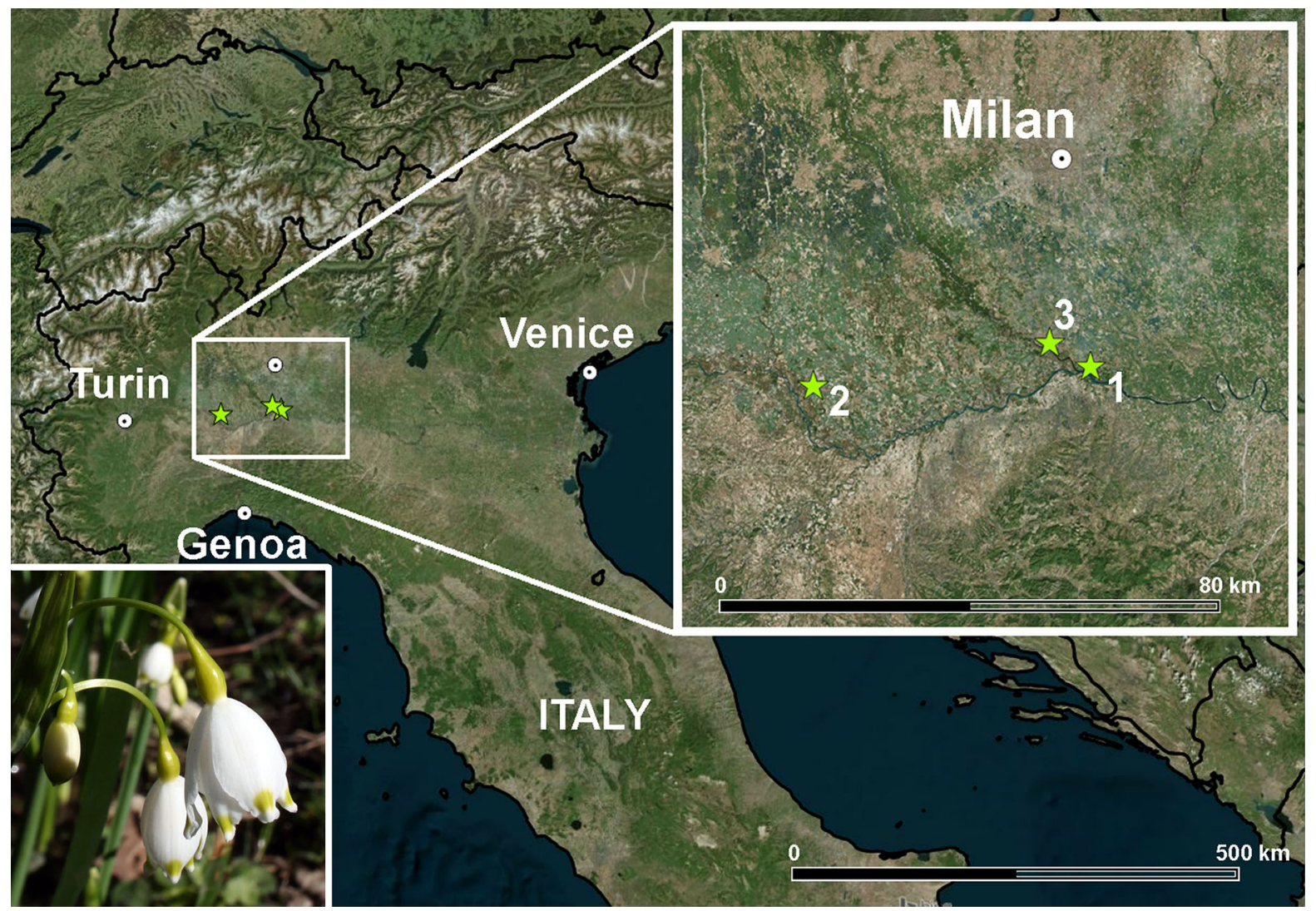

Fig. 1 Map of the study populations in northern Italy. 1. Boschi di Vaccarizza; 2. Bosco Basso; 3. Botanic Garden of the University of Pavia

All collected samples were placed in plastic tubes and frozen waiting to be identified at MUSE-Science Museum of Trento (MUSE). About $70 \%$ of the caught specimens was identified to the species level, ca. $8 \%$ to the genus level, the rest to higher taxonomic levels (family or order). Specimens were identified by using entomological collections available at MUSE and thanks to the cooperation of skilled taxonomists (Supplementary File 1).

Pollen extraction and comparison with Leucojum aestivum pollen grains

At first, we tried to extract, under stereomicroscope, pollen grains directly from the insect's body, but we had little success. Subsequently, we tried the extraction of the pollen attached to the plastic walls of the test tubes by using a few drops of alcohol $99 \% v / v$ for detaching pollen from the tubes. After extraction, pollen grains were placed on a slide for identification by using the optic microscope.

The samples were examined one by one and compared with a sample of $L$. aestivum pollen, taken directly from the flower. The collected arthropods were characterised in terms of feeding habits according to the literature available for each taxon (Gobbi and Latella 2011; Speight 2013; Hoebeke and Wheeler 2013; Losapio et al. 2016; Malmusi et al. 2017) and by the involved skilled taxonomists (Supplementary File 1), then sealed, coded and stored in alcohol 99\% v/ $v$, at the Department of Earth and Environmental Sciences of the University of Pavia.

Statistical analysis

A sample rarefaction analysis was performed using Mao's Tao function in PAST 4.03 (Hammer et al. 2001) to assess the efficacy of the sampling effort in 
detecting arthropods visiting L. aestivum in the study area (Colwell et al. 2012; Gargano et al. 2017).

Two generalised linear models (GLMs) were performed to test the relative importance of the different orders and feeding habits of arthropods found to carry pollen of L. aestivum in the pollination process. Orders were included in the analysis instead of other taxonomic levels because for some specimens the identification could not reach more details. In the GLMs, the quantity of pollen found on each specimen was treated as a dependent variable and "Order" or "Feeding habits" as independent variables.

A specimen containing 200 pollen grains was removed from the analysis because it was considered an outlier. Orders and feeding habits represented by a single specimen were also removed.

The analyses were performed using R-software ( $\mathrm{R}$ Core Team 2018; Fox and Weisenberg 2019).

\section{Results}

The analysis of the catches has returned a high number of different arthropod taxa (i.e. insects and arachnids), direct visitors of L. aestivum or present very close to the flowering plants. In total, 65 catches were made in two years: 39 in 2017 and 26 in 2018.

Overall, catches included 8 orders (plus an unidentified gastropod), 23 families, 20 genera and 18 identified species (Supplementary material 1).

The rarefaction analysis suggested that the sampling effort provided a partial estimation of the

Fig. 2 Result of the rarefaction curve showing the species accumulation curve (number of arthropod taxa as a function of the sampling effort). Dashed lines indicate the $95 \%$ confidence intervals of estimations arthropods visiting $L$. aestivum flowers, as asymptote was not achieved (Fig. 2).

Leucojum aestivum visitors and pollen-carrying arthropods

Thirty three specimens ( $51 \%$ of the total catches) belonging to 18 taxa were found to carry Leucojum pollen (Table 1). Of these, $33 \%$ of the catches were represented by Dasytes plumbeus O.F. Müller, 1776 (Coleoptera, Melyridae). The specimen with the largest number of pollen grains of $L$. aestivum (>200 pollen grains) belonged to Lasioglossum punctatissimum Schenck, 1853 (Hymenoptera, Halictidae) followed by D. plumbeus and Grammoptera ruficornis Fabricius, 1781 (Coleoptera: Cerambycidae) (Table 1).

Concerning the feeding habits, phytophagus s.l. (pollinivorous, antherophagous and nectarivores), predators and omnivorous were the prevalent groups among pollen carriers (Table 1). The GLMs revealed a significant effect of three orders (Coleoptera, Dermaptera and Hymenoptera: $\chi^{2}=199.55 ; \mathrm{df}=6$; $p<0.0001$; Table 2) and a significant effect of two feeding habits (omnivorous and phytophagous s.l.: $\chi^{2}=147.45 ; \mathrm{df}=4 p<0.0001$; Table 2) of arthropods visiting L. aestivum.

Positive catches of L. aestivum pollen were compared with catch days. Figure 3 shows a difference in the maximum number of catches between 2017 and 2018. During these days, there were different weather conditions. On 10/IV/2017, the weather was sunny with the absence of wind. On 05/IV/2017, the weather

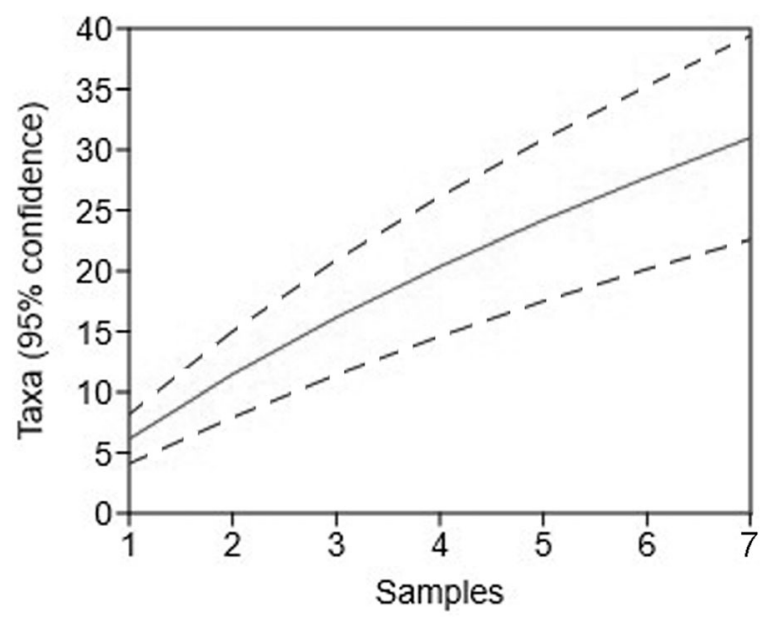


Table 1 Taxa carrying pollen of Leucojum aestivum, number of catches and mean number of pollen grains of L. aestivum found on each taxon

\begin{tabular}{|c|c|c|c|c|c|}
\hline Order & Family & $\begin{array}{l}\text { Species carrying pollen of } \\
\text { Leucojum aestivum }\end{array}$ & $\begin{array}{l}\text { No. of } \\
\text { catches }\end{array}$ & $\begin{array}{l}\text { No. of pollen grains } \\
\text { (mean } \pm \text { st. dev.) }\end{array}$ & Feeding habits \\
\hline Coleoptera & Melyridae & $\begin{array}{l}\text { Dasytes plumbeus Müller, O.F., } \\
1776\end{array}$ & 11 & $12.5 \pm 14.77$ & Antherophagous \\
\hline Araneae & Clubionidae & Clubiona sp. Wagner, 1887 & 2 & $3 \pm 1.41$ & Predator \\
\hline Araneae & Clubionidae & Clubiona pallidula Clerck, 1757 & 2 & $3.5 \pm 0.71$ & Predator \\
\hline Coleoptera & Cerambycidae & $\begin{array}{l}\text { Grammoptera ruficornis Fabricius, } \\
1781\end{array}$ & 2 & $10 \pm 11.31$ & Antherophagous \\
\hline Coleoptera & Nitidulidae & $\begin{array}{l}\text { Lamiogethes pedicularius } \\
\text { Gyllenhal, } 1808\end{array}$ & 2 & $1.5 \pm 0.71$ & Antherophagous \\
\hline Hymenoptera & Halictidae & $\begin{array}{l}\text { Lasioglossum punctatissimum } \\
\text { Schenck, } 1853\end{array}$ & 2 & $101 \pm 140.01$ & Nectarivorous \\
\hline Araneae & Theridiidae & $\begin{array}{l}\text { Enoplognatha cfr. ovata Clerck, } \\
1757\end{array}$ & 1 & 1 & Predator \\
\hline Araneae & Clubionidae & $\begin{array}{l}\text { Clubiona terrestris Westring, } \\
1851\end{array}$ & 1 & 1 & Predator \\
\hline Coleoptera & Melyridae & Clanoptilus sp. Motschulsky, 1853 & 1 & 1 & Antherophagous \\
\hline Dermaptera & Forficulidae & $\begin{array}{l}\text { Apterigyda albipennis von } \\
\text { Muhlfeld, } 1825\end{array}$ & 1 & 8 & Omnivorous \\
\hline Dermaptera & N.D. & N.D. & 1 & 5 & Omnivorous \\
\hline Diptera & Syrphidae & Epistrophe eligans Harris, 1780 & 1 & 2 & Nectarivorous \\
\hline Diptera & Mycetophilidae & N.D. & 1 & 2 & Fungivorous \\
\hline Diptera & Syrphidae & $\begin{array}{l}\text { Platycheirus scutatus Meigen, } \\
1822\end{array}$ & 1 & 1 & Nectarivorous \\
\hline Hymenoptera & Braconidae & N.D. & 1 & 6 & Glycyphagous \\
\hline Hymenoptera & Apidae & $\begin{array}{l}\text { Bombus cfr. ruderatus Fabricius, } \\
1775\end{array}$ & 1 & 2 & Nectarivorous \\
\hline Lepidoptera & Geometridae & $\begin{array}{l}\text { Ematurga atomaria Linnaeus, } \\
1758\end{array}$ & 1 & 2 & Nectarivorous \\
\hline Orthoptera & N.D. & N.D. & 1 & 5 & \\
\hline
\end{tabular}

was cloudy with wind. On 27/IV/2018, the weather was partly cloudy with light wind (See also Supplementary material 2).

\section{Differences among sites}

The most abundant catches of specimens carrying Leucojum pollen were made in the wild population of Vaccarizza, followed by the reintroduced population of Bosco Basso. No Leucojum pollen carriers were found at the Botanical Garden of Pavia (Table 3; Supplementary material 1). Moreover, the site of Vaccarizza resulted to be much richer from a taxonomic point of view than Bosco Basso (Table 3; Supplementary material 1), in which only three specimens, belonging to three different orders, carrying Leucojum pollen were identified (Table 3).
Interestingly, the only shared taxa between the two sites Vaccarizza and Bosco Basso were L. punctatissimum (Hymenoptera, Halictidae) and Enoplognatha cfr. ovata (Araneae, Theridiidae) (Table 3).

\section{Discussion and conclusion}

In this study, we present the most recent account of flower-visiting and pollen-carrying arthropods of $L$. aestivum subsp. aestivum. Among the several visitors caught on L. aestivum plants, we identified 18 taxa that carried Leucojum pollen and that surely have a role as pollinivorous and consequently may have a role as pollinators of this plant species. Interestingly, we highlighted that L. aestivum is visited not only by 
Table 2 Results of the generalised linear model

\begin{tabular}{|c|c|c|c|c|c|}
\hline & & Estimates & St. Error & $Z$ value & $p$ \\
\hline \multirow[t]{7}{*}{ A } & Order & & & & \\
\hline & Araneae & -0.06454 & 0.25820 & -0.250 & 0.80262 \\
\hline & Coleoptera & 1.60944 & 0.09325 & 17.259 & $<0.001$ \\
\hline & Dermaptera & 0.77319 & 0.27735 & 2.788 & 0.00531 \\
\hline & Diptera & -0.58779 & 0.44721 & -1.314 & 0.18873 \\
\hline & Hymenoptera & 0.69315 & 0.31623 & 2.192 & 0.02839 \\
\hline & Lepidoptera & -0.69315 & 0.70711 & -0.980 & 0.32696 \\
\hline \multirow[t]{5}{*}{ B } & Feeding habits & & & & \\
\hline & Omnivorous & 0.77319 & 0.27735 & 2.788 & 0.00531 \\
\hline & Phytophagus s.l & 1.25662 & 0.08771 & 14.328 & $<0.001$ \\
\hline & Predators & -0.12516 & 0.25820 & -0.485 & 0.62785 \\
\hline & Fungivorous & -0.40547 & 0.70711 & -0.573 & 0.56636 \\
\hline
\end{tabular}

(A) role of "Orders" in the transportation of pollen of Leucojum aestivum. Dependent variable is the number of pollen grain found on carriers; (B) role of "Feeding habit" in the transportation of pollen of L. aestivum. Dependent variable is the number of pollen grain found on carriers. Phytophagous s.l. enclosed pollinivorous, nectarivorous, antherophagous and glycyphagous species. Statistically significant effects are in bold

Fig. 3 Frequency of carriers of Leucojum aestivum pollen during the sampling period. Dates are in the format $\mathrm{dd} / \mathrm{mm} / \mathrm{yy}$

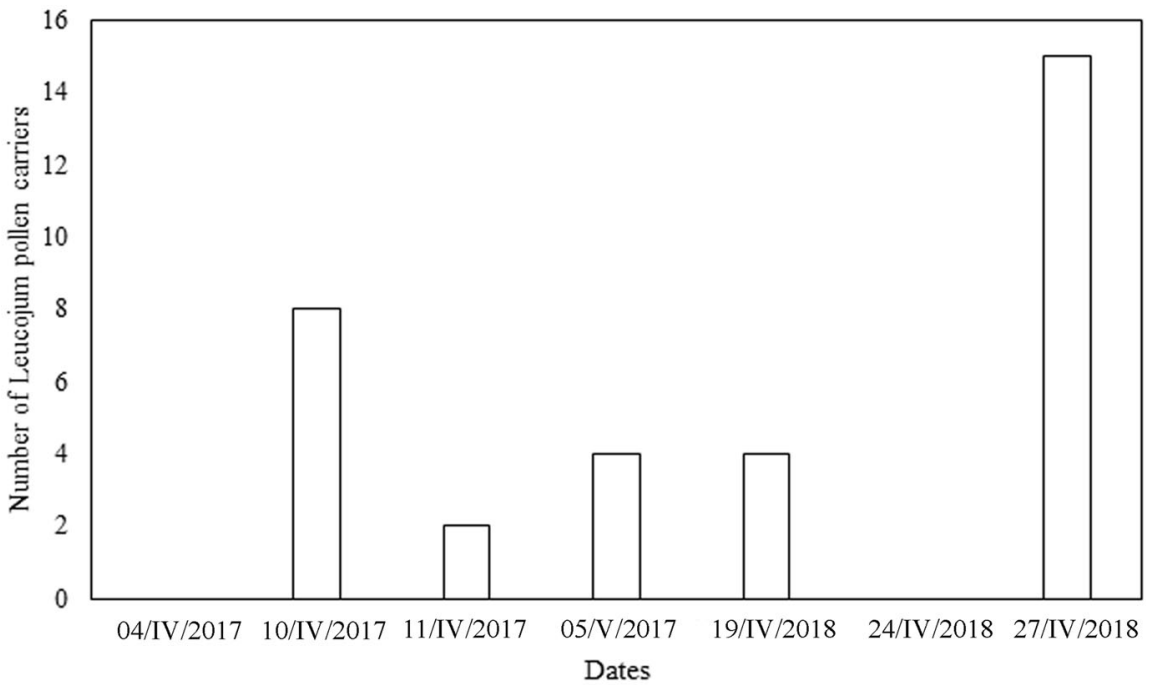

insects, but also by a network of arthropods with different feeding habits (Supplementary material 1).

A diverse array of wild flower visitors can transport viable pollen from a pollen source; data recorded by Rader et al. (2011) demonstrated that two bee genera (Bombus and Lasioglossum) carried pollen at least $300 \mathrm{~m}$ away, while hoverflies carried pollen at least $400 \mathrm{~m}$.

Among the Leucojum pollen carriers, the most commonly found is the melyrid beetle $D$. plumbeus. Hoebeke and Wheeler (2013) report that this species has, on its body, dense setae and pubescence able to trap pollen grains that are transported to other flowers during feeding; adults of $D$. plumbeus are facultative pollen and nectar feeders on various flowers and shrubs and adults are associated with wood (Quercus, Acer, Betula and Picea) in various stages of decomposition and larvae are predators in rotten wood. Its high frequency of occurrence on L. aestivum can be explained by the abundant presence of Quercus robur L. trees on Vaccarizza site which act as source of food for D. plumbeus larvae as well as oviposition sites. An 
Table 3 Leucojum aestivum pollen carriers collecting sites (at the family level)

\begin{tabular}{lllll}
\hline Order & Family & Vaccarizza (wild) & Bosco Basso (reintroduced) & Botanic Garden (ex situ) \\
\hline Araneae & Clubionidae & 1 & 0 & 0 \\
Araneae & Theridiidae & 1 & 1 & 0 \\
Coleoptera & Cerambycidae & 1 & 0 & 0 \\
Coleoptera & Melyridae & 1 & 0 & 0 \\
Coleoptera & Nitidulidae & 0 & 1 & 0 \\
Dermaptera & Forficulidae & 1 & 0 & 0 \\
Dermaptera & N.D. & 1 & 0 & 0 \\
Diptera & Syrphidae & 1 & 0 & 0 \\
Diptera & Mycetophilidae & 1 & 0 & 0 \\
Hymenoptera & Apidae & 1 & 0 & 0 \\
Hymenoptera & Braconidae & 1 & 0 & 0 \\
Hymenoptera & Halictidae & 1 & 1 & 0 \\
Lepidoptera & Geometridae & 1 & 0 & 0 \\
Ortopthera & N.D. & 1 & 0 & 0 \\
Total observations & & 29 & 4 & 0 \\
\hline
\end{tabular}

$1=$ Specimen collected at a site

additional "local" pollinivorous can be considered the long-horned beetle $G$. ruficornis. Similarly to $D$. plumbeus, G. ruficornis has the larval stages linked to some of the species of trees found in Vaccarizza site, for instance Hedera helix L., Robinia pseudoacacia L., Q. robur L., Ulmus campestris Mill., Acer campestre L. (Malmusi et al. 2017).

Other taxa had a significant effect on pollen transport as well as earwigs (Dermaptera) and wild bees (Hymenoptera). Representatives of the latter order were rarely seen foraging on L. aestivum. Most hymenoptera, including bumblebees (Bombus spp.) and carpenter bees (Xylocopa violacea Linnaeus, 1758), observed nearby L. aestivum made quick visits to the flowers probably when searching for nesting places or during foraging activity, as with other deceptive flowers (Tuomi et al. 2015). Indeed, the highest amount of pollen grains was found on $L$. punctatissimum (Hymenoptera), suggesting that this group may be quite efficient in pollination despite the low visitation rate. L. punctatissimum can be considered a good candidate for L. aestivum pollination due to the amount of transported pollen and the quite long distance able to perform that may permit to reach spatially separated populations of L. aestivum. Conversely, to the best of our knowledge, no data on the distance performed by the rest of the sampled taxa are available (Rader et al. 2011).

The potential role of Arachnids in pollination of $L$. aestivum needs further studies. Interestingly, our data highlight the presence of pollen on Clubiona sacspiders (Clubionidae). Clubiona pallidula Clerck, 1757, the spider carrying the highest number of Leucojum pollen grains, is known to find refuge in convolute leaves (Nentwig et al. 2021). Probably, this predator forages and/or finds repair inside the bellshaped Leucojum flowers and if pollination is mediated by arachnids, this should be considered accidental. This hypothesis is supported by the absence, or very low number, of pollen grains in the rest of spider species sampled on the flowers (Table 1).

Visiting arthropods of L. aestivum in our study area are mainly pollen-feeding beetles, as suggested by the GLMs. Interestingly, in contrast to Knuth (1909), we did not observe nocturnal visitations of flowers in our populations. However, we cannot exclude that $L$. aestivum is pollinated also by other taxa (i.e. moths, bees and bumblebees) as reported by Knuth (1909), as we made our observation in a few populations. Visiting arthropod assemblages can greatly differ across the geographic areas and habitat composition where a plant species is found (Péres-Barrales et al. 2007; Gargano et al. 2017). Moreover, a temporal 
decline in spring pollinator assemblage and/or availability (see. Hallmann et al. 2017; Fitzgerald et al. 2021) may also have occurred since Knuth's study.

In the Amaryllidaceae family, different pollinator types were observed, from very specialised species (Geerts and Pauw 2012), with moths (Lepidoptera: Sphingidae) as main pollinators (Manning and Snijman 2002), to less specialised flowers such as in the genus Leucojum or Galanthus. In general, arthropods visitation in L. aestivum is less frequent as in other early-flowering temperate Amaryllidaceae (Baker et al. 2000).

The broader visiting arthropods diversity was detected, as expected, in the wild population of Vaccarizza, followed by the translocated population of Bosco Basso. This pattern reflects the general abundance and diversity of invertebrates caught in the three sites (Supplementary material 1) and is consistent with the characteristics of the sites, with Vaccarizza representing the optimum for the species in a well-preserved alder woodland. The lower number and diversity of pollinators found in the reintroduced population of Bosco Basso is consistent to the observation that pollinator visitations are less frequent in fragmented landscapes (Ward and Johnson 2005). In particular, this site is a quite small and relict alder wood in an intensive farming landscape that may negatively affect the presence of pollinators (Richards 2001). Another difference between Vaccarizza and Bosco Basso is that the former occurs near a farm in the process of converting to organic farming, while the latter is surrounded by conventional farms. Other differences between the two populations such as total population size and density of flowering plants may affect pollinator visitation. Indeed, the entomofauna of the two sites is completely different, with only two shared species. This is an interesting point that should be considered when planning future translocation, i.e. the occurrence in the recipient site of potential pollinator for the translocated species (Draper Munt et al. 2016).

The ex situ population, located in the Botanical Garden, is completely out of context in terms of pollinator availability and assemblage because it is located into a city. However, the lack of observation of L. aestivum pollen carriers is difficult to be explained, considering that this population do set seed every year (T.A. personal observation). It is possible that our observation protocol failed to recognise some pollinators in this specific artificial habitat, also considering that the collected sample was only partially representative of the potential pollinator assemblage (Fig. 2). Alternatively, as observed by Geerts and Pauw (2012), we cannot exclude the presence of hawk moths (Sphingidae) as main pollinators in the Botanical Garden. Hawk moths are quite common in urban areas as visitors of city flower (Albu and Albu 2016); thus, probably a higher number of sampling sessions would have increased the probability to observe specimens belonging to this family.

In conclusion, we identified 18 visiting and pollencarrying arthropods that can potentially act as pollinators of $L$. aestivum in N-Italy, with pollen-feeding Coleoptera the most frequent taxa involved in the pollination of this plant and mining bee L. punctatissimum as the species with the highest number of pollen grains stuck to its body. A recent paper published by Bonelli et al. (2020) demonstrated the importance and potentialities to combine manual sampling to video observations with the purpose to estimate the diversity of flower-visiting arthropods, to spot rare taxa and to evaluate which taxa could be involved in its pollination. Thus, a follow-up of this project, or more in general researches aimed at investigating pollination processes on plants with short flowering period, could be to apply both the sampling methods.

Although our study is limited to a small portion of the range of $L$. aestivum, and a standardised method for detecting pollen grains on the arthropod body parts has not been published, this is the first recent contribution to the study of pollinators in this species and in the genus Leucojum.

Acknowledgements Authors are grateful to Gianalberto Losapio (Standford University) for his suggestions on the statistical analysis. Dr. Christopher Calvi, Dr. Maria Chiara Mariani, Dr. Paolo Cauzzi (Pavia) for their help provided during field observations. Authors also thank all the specialists that contributed to the identification of some of the specimens (Supplementary material 1).

Author contributions TA and GR conceived the experiment, LAV and TA carried out the field work, MG supervised the identification of the specimens. All authors wrote parts of the manuscript.

Funding Open access funding provided by Università degli Studi Roma Tre within the CRUI-CARE Agreement. The Grant of Excellence Departments, MIUR-Italy (ARTICOLO 1, COMMI 314-337 LEGGE 232/2016) is gratefully acknowledged for support provided to TA. 
Data availability Raw data used in this study are available in the Supplementary material 1 and 2.

\section{Declarations}

Conflict of interest The authors declared that they have no competing interest.

Open Access This article is licensed under a Creative Commons Attribution 4.0 International License, which permits use, sharing, adaptation, distribution and reproduction in any medium or format, as long as you give appropriate credit to the original author(s) and the source, provide a link to the Creative Commons licence, and indicate if changes were made. The images or other third party material in this article are included in the article's Creative Commons licence, unless indicated otherwise in a credit line to the material. If material is not included in the article's Creative Commons licence and your intended use is not permitted by statutory regulation or exceeds the permitted use, you will need to obtain permission directly from the copyright holder. To view a copy of this licence, visit http://creativecommons.org/licenses/by/4.0/.

\section{References}

Abeli T, Jäkäläniemi A, Wannas L, Mutikainen P, Tuomi J (2013) Pollen limitation and fruiting failure related to canopy closure in Calypso bulbosa (Orchidaceae), a northern food-deceptive orchid with a single flower. Bot J Linnean Soc 171:744-750. https://doi.org/10.1111/boj. 12014

Abeli T, Cauzzi P, Rossi G, Adorni M, Vagge I, Parolo G, Orsenigo S (2016) Restoring populations structure and dynamics in translocated species: learning from wild populations. Plant Ecol 217:183-192. https://doi.org/10. 1007/s11258-015-0529-x

Albu V, Albu S (2016) Contributions to the knowledge of the Lepidoptera species diversity in an urban park setting of Bucharest, Romania, with considerations on the species dynamics in the city over the last century. Entomol Rom 20:69-78

Alonso C (2004) Early blooming's challenges: extended flowering season, diverse pollinator assemblage and the reproductive success of gynodioecious Daphne laureola. Ann Bot 93:61-66

Aschan G, Pfanz H (2006) Why snowdrop (Galanthus nivalis L.) tepals have green marks? Flora 201:623-632

Baker AM, Barrett SC, Thompson JD (2000) Variation of pollen limitation in the early flowering mediterranean geophyte Narcissus assoanus (Amaryllidaceae). Oecologia 124:529-535

Bonelli M, Melotto A, Minici A, Eustacchio E, Gianfranceschi L, Gobbi M, Casartelli M, Caccianiga M (2020) Manual sampling and video observations: an integrated approach to studying flower-visiting arthropods in high-mountain environments. Insects 11:881
Brittain CA, Vighi M, Bommarco R, Settele J, Potts SG (2010) Impacts of a pesticide on pollinator species richness at different spatial scales. Basic Appl Ecol 11:106-115

Clauser M, Pavone P (2016) Orti botanici, eccellenze Italiane. Nuove Direzioni, Firenze

Colwell RK, Chao A, Gotelli NJ, Lin SY, Mao CX, Chazdon RL, Longino JT (2012) Models and estimators linking individual-based and sample-based rarefaction, extrapolation and comparison of assemblages. J Plant Ecol 5:3-21

Dauber J, Biesmeijer JC, Gabriel D, Kunin WE, Lamborn E, Meyer B, Settele J (2010) Effects of patch size and density on flower visitation and seed set of wild plants: a panEuropean approach. J Ecol 98:188-196

Draper Munt D, Marques I, Iriondo JM (2016) Acquiring baseline information for successful plant translocations when there is no time to lose: the case of the neglected critically endangered Narcissus cavanillesii (Amaryllidaceae). Plant Ecol 217:193-206

Fishchuk OS, Odintsova AV (2020) Micromorphology and anatomy of the flowers of Galanthus nivalis and Leucojum vernum (Amaryllidaceae). Reg Mec 11:463-468

Fitzgerald JL, Stuble KL, Nichols LM, Diamond SE, Wentworth TR, Pelini SL, Gotelli NJ, Sanders NJ, Dunn RR, Penick CA (2021) Abundance of spring-and winter-active arthropods declines with warming. Ecosphere 12(4): 03473

Fox J, Weisberg S (2019) An R companion to applied regression, 3rd edn. Thousand Oaks, California

Gargano D, Fenu G, Bernardo L (2017) Local shifts in floral biotic interactions in habitat edges and their effect on quantity and quality of plant offspring. AoB Plants. https:// doi.org/10.1093/aobpla/plx031

Geerts S, Pauw A (2012) The cost of being specialized: pollinator limitation in the endangered geophyte Brunsvigia litoralis (Amaryllidaceae) in the cape floristic region of South Africa. S Afr J Bot 78:159-164

Gentili R, Abeli T, Parolo G, Ciappetta S, Montagnani C, Muller JV, Rossi G, Citterio S (2018) Genetic structure of Leucojum aestivum $\mathrm{L}$. in the Po Valley (N-Italy) drives conservation management actions. Conserv Genet 19:827-838

Gobbi M, Latella L (2011) La fauna dei prati -1: tassonomia, ecologia e metodi di studio dei principali gruppi di invertebrati terrestri italiani. Quaderni del Museo delle Scienze, Trento

Hallmann CA, Sorg M, Jongejans E, Siepel H, Hofland N, Schwan H, Stenmans W, Muller A, Sumser H, Horren T, Goulson D, de Kroon H (2017) More than 75 percent decline over 27 years in total flying insect biomass in protected areas. PloS one 12:e0185809

Hammer Ø, Harper DA, Ryan PD (2001) PAST: paleontological statistics software package for education and data analysis. Palaeontol Electron 4(1):1-9

Hoebeke ER, Wheeler AG Jr (2013) Dasytes plumbeus (Müller)(Coleoptera: Melyridae: Dasytinae), a palearctic softwinged flower beetle new to North America. Zootaxa 3717:377-382

Kasermann C, Moser DM (1999) Fiches pratiques pour la conservation. Plantes à fleur et fourgères. OFEFP, Switzerland 
Knuth P (1909) Handbook of flower pollination: based upon Hermann Müller's work 'The fertilisation of flowers by insects,' vol 3. Clarendon Press, Oxford

Lansdown RV (2014) Leucojum aestivum. The IUCN red list of threatened species 2014: e.T164488A45461549. https:// doi.org/10.2305/IUCN.UK.2014-1.RLTS. T164488A45461549.en. Downloaded on 04 May 2021

Losapio G, Gobbi M, Marano G, Avesani D, Boracchi P, Compostella C, Pavesi M, Schob C, Seppi R, Sommaggio D, Zanetti A, Caccianiga M (2016) Feedback effects between plant and flower-visiting insect communities along a primary succession gradient. Arthropod-Plant Inte 10:485-495

Malmusi M, Saltini L, Poloni R (2017) Nuovo contributo alla redazione di un Catalogo dei Vesperidae e dei Cerambycidae dell'Emilia. Atti Soc Nat Mat Modena 148:241-274

Manning JC, Snijman D (2002) Hawkmoth-pollination in Crinum variabile (Amaryllidaceae) and the biogeography of sphingophily in southern African Amaryllidaceae. S Afr J Bot 68:212-216

Nentwig W, Blick T, Bosmans R, Gloor D, Hänggi A, Kropf C (2021) Spiders of Europe. Version 1.2021. Online at: https://www.araneae.nmbe.ch. Accessed on 16 Jan 2021

Orsenigo S, Fenu G, Gargano D, Montagnani C, Abeli T et al (2021) Red list of threatened vascular plants in Italy. Plant Biosyst 155:310-335

Parolo G, Abeli T, Rossi G, Dowgiallo G, Matthies D (2011) Biological flora of Central Europe: Leucojum aestivum L. Perspect Plant Ecol 13:319-330

Pérez-Barrales R, Arroyo J, Scott Armbruster W (2007) Differences in pollinator faunas may generate geographic differences in floral morphology and integration in
Narcissus papyraceus (Amaryllidaceae). Oikos 116:1904-1918

R Core Team (2018) R: a language and environment for statistical computing. R Foundation for Statistical Computing, Vienna. https://www.R-project.org. Accessed 29 June 2021

Rader R, Edwards W, Westcott DA, Cunningham SA, Howlett BG (2011) Pollen transport differs among bees and flies in a human-modified landscape. Divers Distrib 17:519-529

Richards AJ (2001) Does low biodiversity resulting from modern agricultural practice affect crop pollination and yield? Ann Bot 88:165-172

Speight MCD (2013) Species accounts of European Syrphidae (Diptera), 2013. Syrph the net, the database of European Syrphidae. Syrph the Net publications, Dublin

Tuomi J, Lamsa J, Wannas L, Abeli T, Jakalaniemi A (2015) Pollinator behaviour on a food-deceptive orchid Calypso bulbosa and co-flowering species. Sci World J. https://doi. org/10.1155/2015/482161

Ward M, Johnson SD (2005) Pollen limitation and demographic structure in small fragmented populations of Brunsvigia radulosa (Amaryllidaceae). Oikos 108:253-262

Wisdom MM, Richardson MD, Karcher DE, Steinkraus DC, McDonald GV (2019) Flowering persistence and pollinator attraction of early-spring bulbs in warm-season lawns. HortScience 54:1853-1859

Publisher's Note Springer Nature remains neutral with regard to jurisdictional claims in published maps and institutional affiliations. 